\title{
Epithelium-Specific ETS (ESE)-1 upregulated GP73 expression in hepatocellular carcinoma cells
}

\author{
Fang Wang ${ }^{1}$, Qi Long ${ }^{1}$, Yu Gong ${ }^{1,5}$, Longbo Hu ${ }^{1}$, Hong Zhang ${ }^{3}$, Peter Oettgen ${ }^{4}$ and Tao Peng 1,2*
}

\begin{abstract}
Background: Golgi protein-73 (GP73) is a Golgi transmembrane glycoprotein elevated in numerous liver diseases. Clinically, GP73 is strongly elevated in the serum of HCC patients and is thus regarded as a novel potential biomarker for HCC. However, the mechanism leading to GP73 dysregulation in liver diseases remains unknown.

Results: This study determined that epithelium-specific ETS (ESE)-1, an epithelium-specific transcription factor, and GP73 expressions were induced by IL-1 $\beta$ stimulation in vitro, and both were triggered during liver inflammation in vivo. In hepatocellular carcinoma cells, the overexpression of ESE-1 induced GP73 expression, whereas its knock-down did the opposite. Mechanistically, ESE-1 activated GP73 expression by directly binding to its promoter.

Conclusions: Our findings supported a novel paradigm for ESE-1 as a transcriptional mediator of GP73. This study provided a possible mechanism for GP73 upregulation in liver diseases.
\end{abstract}

Keywords: GP73, GOLPH2, GOLM1, ESE-1, Liver inflammation, HCC

\section{Background}

Golgi protein-73 (GP73), also known as GOLPH2 or GOLM1, is a type II Golgi transmembrane glycoprotein [1] and is predominantly expressed in epithelial cells [2]. It is upregulated in numerous liver diseases, including virusinduced hepatitis (e.g., hepatitis B and C virus), alcoholinduced liver disease, autoimmune hepatitis $[3,4]$, liver cirrhosis [4], and hepatocellular carcinoma cells (HCC) [5-7]. Clinically, GP73 is strongly elevated in the serum of HCC patients [8] and is thus regarded as a novel potential biomarker for HCC [5-7].

Previous studies showed that GP73 is induced under inflammatory conditions [3,9-11]. In HepG2 and Hep3B cells, GP73 expression is elevated after treatment with proinflammatory cytokine IL-6 [9]. Increased GP73 expression in SK-Hep-1 cells is associated with interferon gamma (IFN- $\gamma$ ) stimulation [3]. In vivo, GP73 is upregulated in a mouse model of $\mathrm{CCl}_{4}$-induced cirrhosis [10]. However, the mechanism by which these extracellular signals trigger GP73 expression remains unclear.

\footnotetext{
* Correspondence: pengtao@gzhmu.edu.cn

'State Key Laboratory of Respiratory Disease, Guangzhou Institutes of Biomedicine and Health, Chinese Academy of Sciences, Guangzhou 510530, China

${ }^{2}$ Guangzhou Hoffmann Institute of Immunology, College of Basic Sciences, Guangzhou Medical University, Guangzhou 510182, China

Full list of author information is available at the end of the article
}

ESE-1, also known as ELF-3, is a member of ESE subfamily of ETS transcription factors. It is exclusively expressed in epithelial cells and mainly contains two putative DNA binding domains, namely, the ETS and A/T hook domains [12]. Its ETS domain commonly binds a core consensus sequence of GGAA [13]. Similar to GP73, ESE-1 is also induced by proinflammatory factors such as IL-1 $\beta$, tumor necrosis factor- $\alpha$ [14], and lipopolysaccharide (LPS) $[15,16]$. Moreover, proinflammatory cytokine IL-1 $\beta$ induces ESE-1 expression in chondrocytes [17] and prostate cancer cells [18].

In this study, we demonstrated that similar to ESE-1, GP73 expression was also induced upon IL-1 $\beta$ stimulation, and was upregulated by ESE-1 in HCC cells. Mechanistically, we identified that ESE-1 activated GP73 expression by directly binding to its promoter. Thus, ESE-1 was a novel transcriptional regulator of GP73 in liver diseases.

\section{Results}

IL-1 $\beta$ stimulated both ESE-1 and GP73 expressions Previous studies reported that under inflammatory conditions, GP73 expression is elevated in hepatocytes [3,9]. Since ESE-1, an epithelial specific transcription factor, is also induced by proinflammatory cytokine IL-1 $\beta[17,18]$, 
we asked whether ESE-1 played a role in the regulation of GP73 expression. By first comparing the basal levels of ESE-1 and GP73 proteins in different HCC cell lines (HepG2, Hep3B, Huh7), we found that Huh7 cells with high level of ESE-1 protein exhibited high level of GP73, whereas HepG2 cells with minimal ESE-1 protein showed minimal GP73 (Figure 1A). Similar correlation of ESE-1 and GP73 expression was also observed in other human and mouse hepatocytes (Additional file 1: Figure S1). To determine whether the expression of GP73 is also stimulated by IL-1 $\beta$, Hep3B and Huh7 cells were subsequently treated with different doses of IL-1 $\beta$. Both qPCR and Western blot analyses indicated that compared with the untreated control in Hep3B (Figure 1B) and Huh7 (Figure 1C) cells, ESE-1 was increased after IL-1 $\beta$ treatment, and that GP73 was also increased in a dose-dependent manner. These results indicated that ESE-1 and GP73 were induced in response to IL-1 $\beta$ stimuli.

To determine ESE-1 and GP73 expressions under proinflammatory conditions in vivo, a mouse liver inflammation model was used. Mice were intraperitoneally injected with LPS and D-galactosamine [19]. Mice sera were collected at different time points, and the levels of alanine aminotransferase (ALT) and aspartate aminotransferase (AST) were measured. The levels of ALT and AST, as the criteria for inflammation response, peaked at $6 \mathrm{~h}$ post injection, suggesting that liver inflammation was induced. Inflammation was recovered after $72 \mathrm{~h}$, as indicated by the decreased ALT and AST elevation (Figure 2A). The liver tissues of the mice were collected at different time points, and the mRNA levels of ESE-1 and GP73 were analyzed using qPCR. ESE-1 expression peaked at $12 \mathrm{~h}$, whereas GP73 expression peaked at $24 \mathrm{~h}$. Both expressions finally recovered to normal level within $72 \mathrm{~h}$ (Figure $2 \mathrm{~B}$ ). The results of immunohistochemical analysis verified that GP73 expression was induced by liver inflammation (Figure 2C).

Next, we determined ESE-1 and GP73 expressions in human HCC tissue samples using immunofluorescence with serial sections of samples. HE staining was used to present the pathological changes in liver tissues. Consistent with the previous reports, GP73 was located in the Golgi body [20], whereas ESE-1 was distributed in the cytoplasm [21,22]. The regions with higher expression level of ESE-1 also showed higher GP73 expression, whereas in the para-carcinoma tissue, both proteins displayed lower expressions. The isotype-matched control samples exhibited no staining (Figure 3).

These studies collectively identified that ESE- 1 and GP73 expressions were induced in response to IL-1 $\beta$ stimuli in vitro and were triggered during liver inflammation in vivo. Both expressions were elevated in HCC patient samples.
A

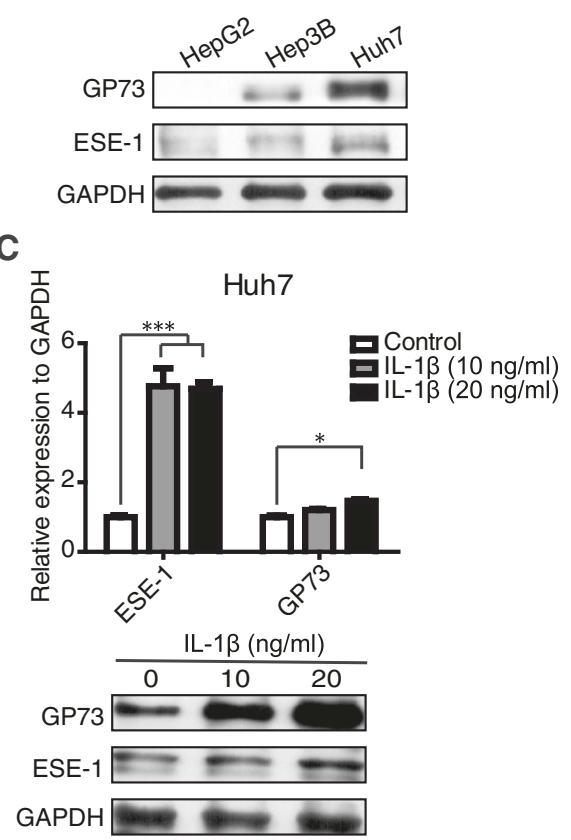

B

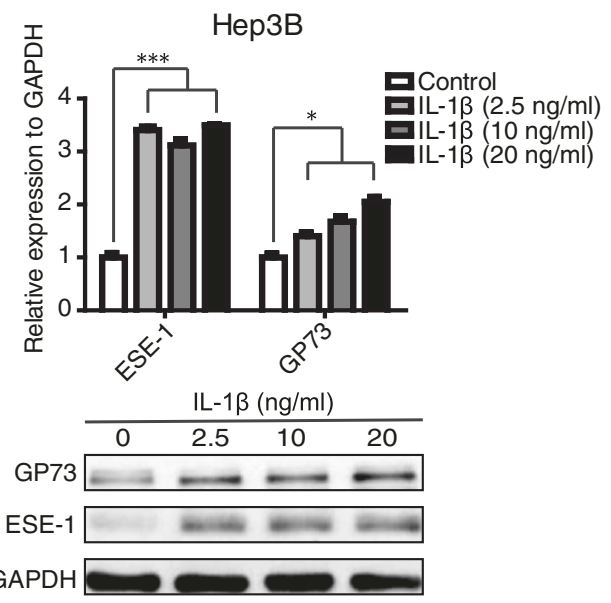

Figure 1 ESE-1 and GP73 expressions were induced by IL-1 $\beta$ stimulation in vitro. (A) The basal levels of ESE-1 and GP73 expressions in HepG2, Hep3B, and Huh7 cells were analyzed by conducting Western blot. (B) Hep3B cells were stimulated with different doses of IL-1 3 (2.5, 10, and $20 \mathrm{ng} / \mathrm{mL}$ ) for $48 \mathrm{~h}$. IL-1 $\beta$-induced ESE-1 and GP73 mRNA and protein levels were analyzed by performing qPCR and Western blot. (C) Huh7 cells were stimulated with different doses of IL-1 3 (10 and $20 \mathrm{ng} / \mathrm{mL}$ ) for $48 \mathrm{~h}$. ESE-1 and GP73 mRNA and protein levels were analyzed with qPCR and Western blot. The values were normalized to GAPDH. Western blot was reprobed for GAPDH as a loading reference control. 


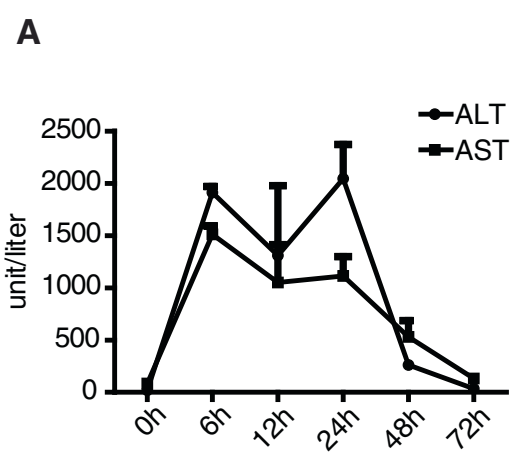

C

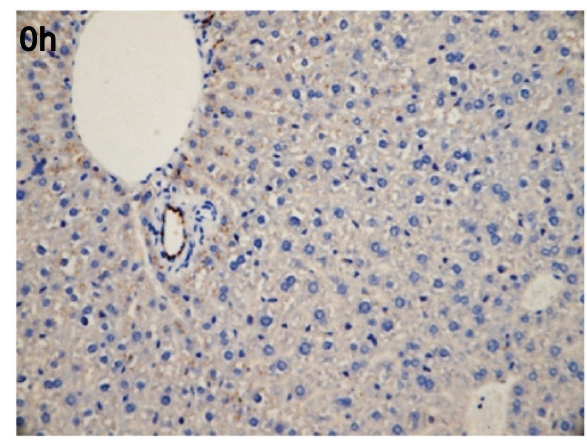

B
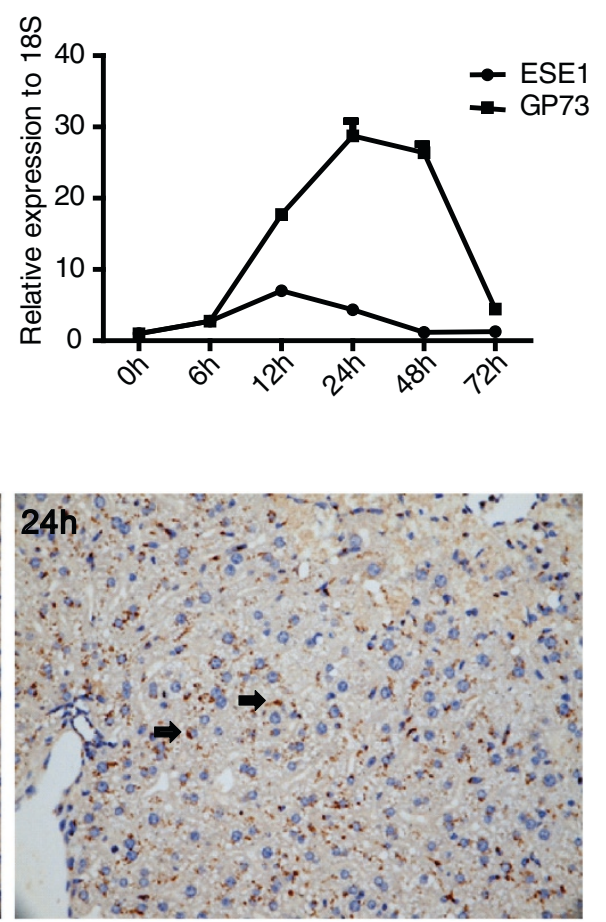

Figure 2 ESE-1 and GP73 expressions were triggered during liver inflammation in vivo. The mouse liver inflammation model was constructed by intraperitoneally injecting LPS (35 ng/ $\mathrm{kg}$ ) and D-galactosamine $(250 \mathrm{mg} / \mathrm{kg}$ ). (A) The levels of ALT and AST in mice sera were measured by full automatic blood analyzer at different time points during liver inflammation. (B) The mRNA levels of mouse ESE-1 and GP73 in liver tissues were measured with qPCR. (C) Mouse GP73 expression levels in liver tissues were analyzed at 0 and $24 \mathrm{~h}$ by accomplishing immunohistochemistry. Black arrows depicted the location of GP73 protein.

\section{ESE-1 upregulated GP73 expression in HCC cells}

As previously indicated, ESE-1 and GP73 expressions were induced by IL-1 $\beta$ stimulation in vitro. We wondered whether ESE-1 regulated GP73 expression. An ESE-1 expression plasmid was constructed, and its expression was confirmed by transfecting pCR3.1-ESE-1 plasmid into 293T cells (Figure 4A). When ESE-1 was overexpressed in Hep3B cells, the transcript and protein levels of GP73 increased accordingly (Figure 4B). Similar results were also confirmed in Huh7 cells (Figure 4C).

To further confirm that ESE-1 is responsible for the elevated GP73 expression, a mutant form of ESE-1 [12] (lacking ETS domain, which was required for ESE-1 binding) ( $\triangle \mathrm{ESE}-1)$ was constructed (Figure 4D). Compared with ESE-1, the upregulatory effect on GP73 of $\triangle \mathrm{ESE}-1$ was impaired in Hep3B and Huh7 cells (Figure 4E). These findings signified that ESE-1 overexpression increased GP73 expression.

By preparing an efficient retroviral shRNA vectors for ESE-1, we also assessed whether ESE-1 upregulated GP73 expression in the presence of IL-1 $\beta$. The transcript and protein levels of GP73 decreased with ESE-1 knockdown in Hep3B (Figure 4F) and Huh7 cells (Figure 4G) with or without IL-1 $\beta$. GP73 protein level recovered after
ESE-1 expression in both knock-down cells (Figure 4H and I). These results indicated that ESE-1 upregulated GP73 expression.

\section{ESE-1 bound to and activated GP73 promoter}

To illustrate details of how ESE-1 regulated GP73 expression, ESE-1 (or $\triangle \mathrm{ESE}-1$ ) and GP73 promoter reporter vectors were co-transfected into hepatocytes, Huh7 and Hep3B. We found that ESE-1 but not $\triangle \mathrm{ESE}-1$ efficiently activated GP73 promoter (Figure 5A and B). Moreover, ESE-1 activated GP73 promoter in a dosedependent manner (Figure $5 \mathrm{C}$ ). These results indicated that ESE-1 activated GP73 promoter.

Based on the ESE-1 binding core sequences, the possible ESE-1 binding sites were predicted in regions I $(-1110 /-864)$, III $(-734 /-421)$, and IV $(-421 /-79)$ of GP73 promoter (Figure 5D, upper panel). To confirm that ESE-1 directly interacted with GP73 promoter, the specific binding of ESE-1 to these DNA sequences was analyzed with ChIP assay, followed by qPCR. Compared with the IL-1 $\beta$ untreated control, ESE-1 loading onto the corresponding promoters was significantly enhanced after IL-1 $\beta$ stimulation (Figure 5D, lower panel), indicating that ESE-1 bound to the three 


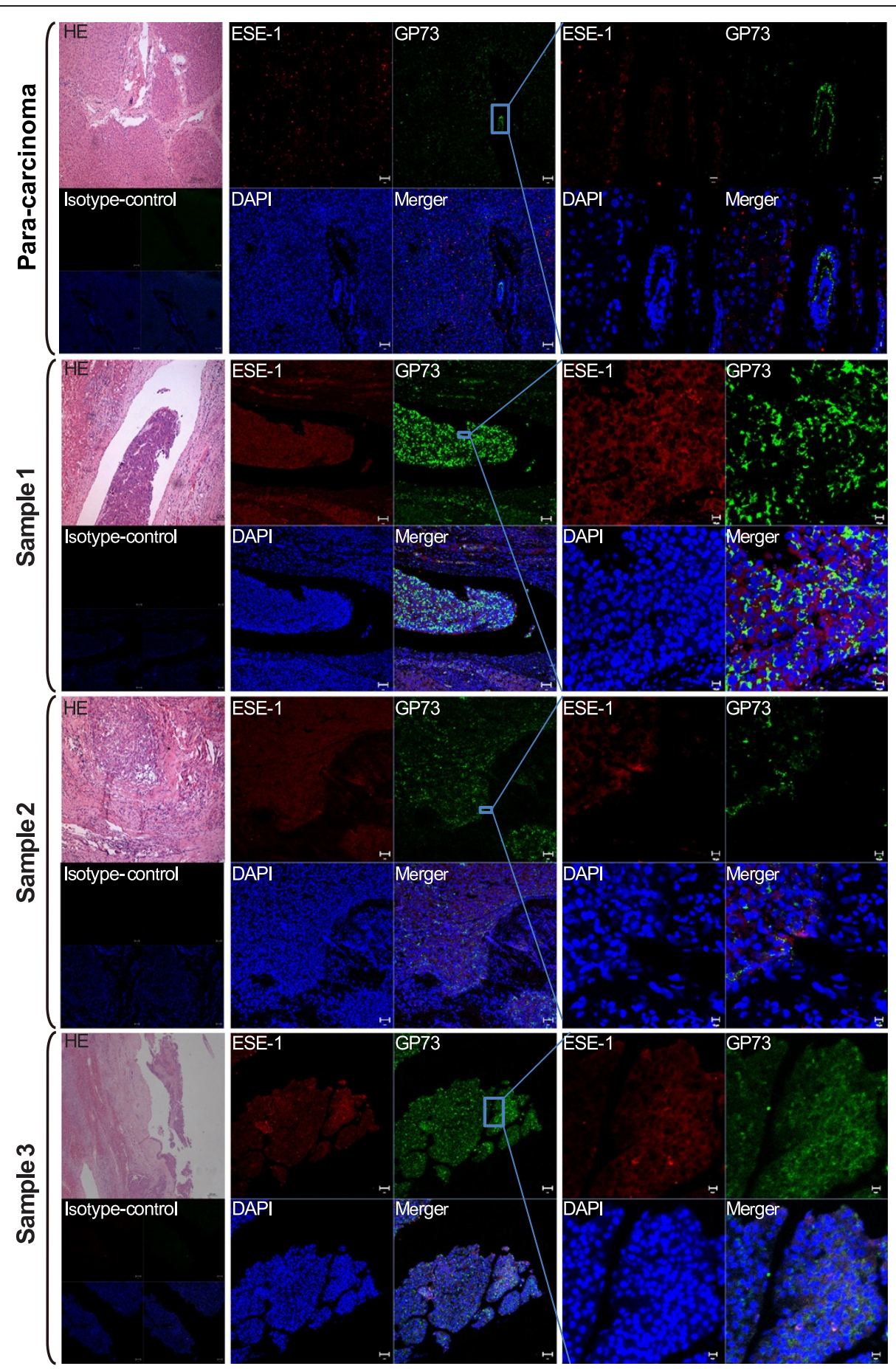

Figure 3 ESE-1 and GP73 were elevated in the liver tissues of patients with HCC. Liver tissues of HCC patients $(n=5)$ were collected and fixed by formaldehyde. Hematoxylin-eosin (HE) staining was used to present the pathological changes in liver tissues. ESE-1 (red fluorescence) and GP73 (green fluorescence) expression levels were analyzed by conducting immunofluorescence. Nuclei (blue fluorescence) were counterstained with DAPI. The isotype-matched lgG was used as a negative control.

predicted binding sites of GP73 promoter, and this binding activity was strongly enhanced by IL-1 $\beta$ treatment.

To further confirm that ESE-1 could bind to the three regions of GP73 promoter, the corresponding deletion mutants were constructed in these regions by deleting the two adjacent possible ESE-1 binding sites. $\Delta-989 /-$ 965 and $\Delta-918 /-869$ deletion mutants were located in region I; $\Delta-617 /-583$ was located in region III; and $\Delta-$ 


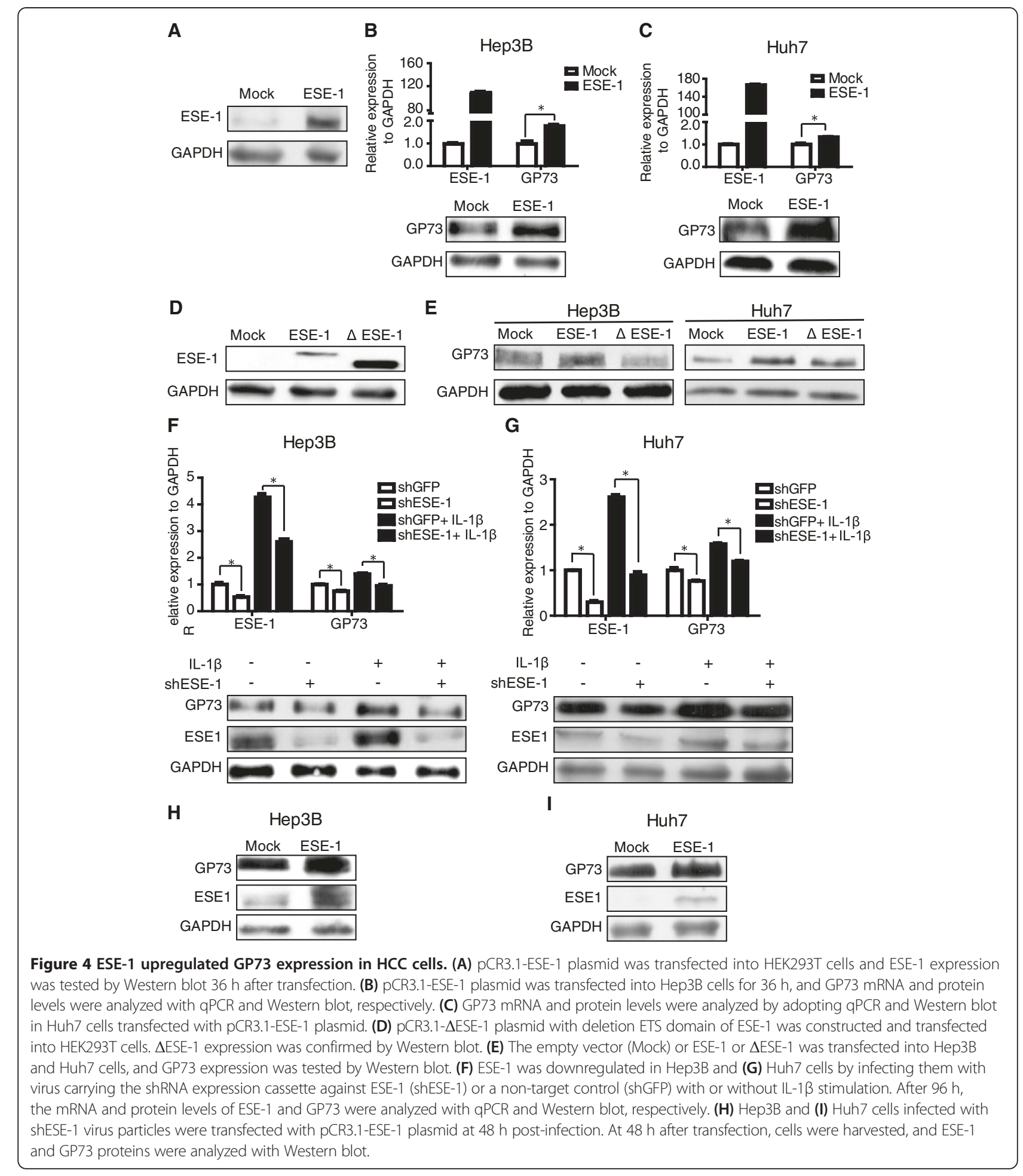

$351 /-365$ and $\Delta-261 /-232$ were located in region IV. ESE-1 and GP73 full-length promoter (or deletion mutant promoters) were co-transfected into Hep3B cells. The results of luciferase reporter assays demonstrated that the activities of $\Delta-918 /-869$ and $\Delta-617 /-583$ mutant promoters were impaired compared with that of the GP73 full-length promoter, whereas the activity of $\Delta-351 /-365$ was enhanced (Figure 5E). Therefore, ESE-1 could bind to regions I and III with activating effect and region IV with repressive activity. These results demonstrated that ESE-1 bound to GP73 promoter in multiple binding sites, which was consistent with the results of the ChIP-qPCR assay. 


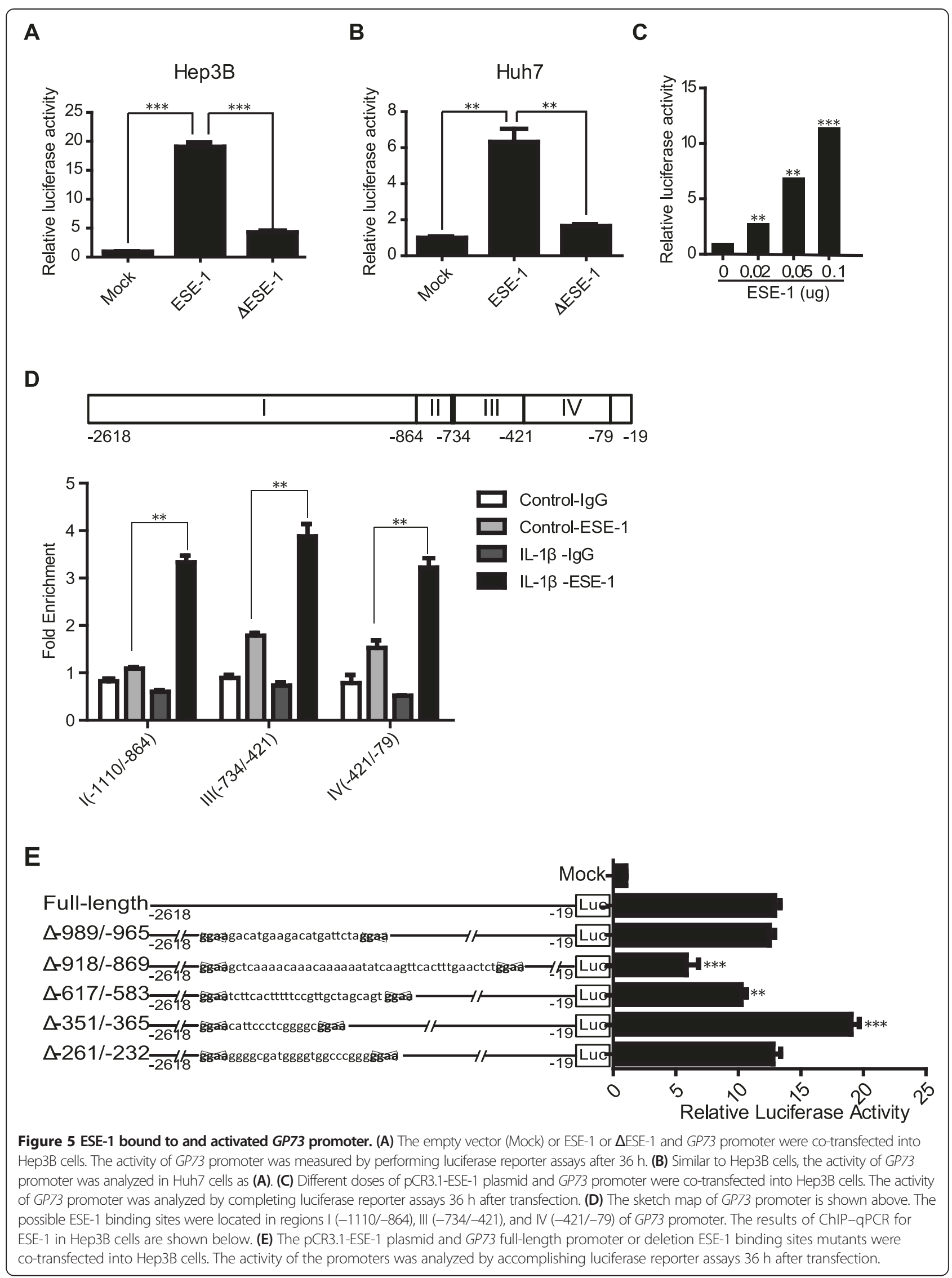


The above findings collectively attested that ESE-1 upregulated GP73 expression in HCC cells by directly binding to and activating its promoter.

\section{Discussion}

GP73 is elevated in many liver diseases and is considered a potential biomarker for HCC. However, little information is known about the mechanism leading to elevated GP73 expression in liver diseases. Therefore, understanding the mechanism of GP73 upregulation is of importance to develop better diagnostic and therapeutic methods. The aim of this study is to investigate the underlying mechanism of GP73 upregulation in liver diseases.

GP73 expression is up-regulated in various hepatitis and HCC, with the highest in serum of HCC patients [7]. Many studies reported that HCC can be promoted and exacerbated by inflammation [23-26]. Chronic inflammation is associated with persistent hepatic injury and regeneration, leading to sequential development of fibrosis, cirrhosis, and eventually HCC. Recently, several inflammation-related signaling pathways, such as the nuclear factor-kappa B and signal transducer and activator of transcription pathways, have been identified as key players in these processes. To reveal the regulation mechanism of GP73 expression in liver diseases, we analyzed GP73 expression in HCC cells under inflammation conditions. We found that GP73 expression was upregulated upon IL-1 $\beta$ stimulation in vitro (Figure 1 ) and was triggered during liver inflammation in vivo (Figure 2). These findings conformed to previous stipulation that GP73 is upregulated under inflammatory conditions. The regulation mechanism of GP73 expression was further realized by seeking for the key transcription factors. We discovered that ESE-1 could significantly activate GP73 promoter (Figure 5A). Based on the fact that both ESE-1 and GP73 are expressed in epithelial cells [2,12], and both are induced in response to IL- $1 \beta$ stimuli, our findings suggest that ESE-1 is at least one of the regulatory links between the inflammatory stimuli and the enhanced GP73 expression.

Since the ETS domain of ESE-1 is responsible for DNA binding, it is reasonable that the upregulatory effect on GP73 of $\triangle E S E-1$ was impaired when compared with ESE-1 in Hep3B and Huh7 cells (Figure 4E). However, recent studies showed that the ETS domain of ESE-1 also mediated the protein-protein interactions [27], and ESE-1 also contains a Pointed domain [12], an $\mathrm{A} / \mathrm{T}$ hook domain [12], and a serine- and aspartic acidrich domain [21]. Therefore, it is not surprising to find that $\triangle \mathrm{ESE}-1$ overexpression in Hep3B and Huh7 cells showed minor discrepancy in inducing GP73 expression compared with mock (Figure 4E), which is probably related to different partners interacted with ESE-1 through different domains in different cell context [27]. Multiple ETS sites, including regions I (-1110/-864), III (-734/-421), and IV $(-421 /-79)$, were predicted on GP73 promoter based on the ESE-1 binding core sequence. The results of the ChIP-qPCR assay (Figure 5D) and deletion ESE1 binding site mutants (Figure 5E) confirmed that multiple ESE-1 binding sites were available in GP73 promoter. Similar results of a regulatory region with several ETS binding sites are observed in other ESE-1 regulated genes, such as SPRR2A, Endo A [12], TGF- $\beta$ II receptor [28], COX2 [15], and COL2A1 [17]. The observation of impaired activities by $\Delta-918 /-869$ and $\Delta-617 /-583 \mathrm{mu}-$ tants and the enhanced activity by $\Delta-351 /-365$ mutant (Figure 5E) suggested that ESE-1 could interact with either co-activators or co-repressors and may result in different responses. This postulation was supported by the fact that ESE-1 represses target gene expression by interacting with Ku70 and Ku86 proteins, but yields such expression by interacting with p300 and CREB-binding proteins [27].

In HCC, GP73 is upregulated in liver tissue and serum [5-7]. However, the role of ESE-1 in HCC has never been reported. This is the first report of the correlation between ESE-1 and HCC. Previous studies suggested that the intercellular location of ESE-1 is determined by nuclear localization and nuclear export signals [21,22]. We found that ESE-1 located in cytoplasm and nuclear in Hep3B and Huh7 cells, regardless of IL- $1 \beta$ stimulation (Additional file 2: Figure S2). Nevertheless, ESE-1 was mainly distributed in the cytoplasm in liver tissue of HCC patients, which is consistent with the location of ESE-1 in human breast cancer [21,22]. Additionally, ESE-1 and GP73 expressions were identified to be elevated and exhibited similar distribution in the liver tissue of HCC patients (Figure 3). Importantly, ESE-1 is upregulated in human cancers and prompts cancer development $[18,29,30]$. These findings were important in understanding the role of GP73 in HCC development and progression.

The results of this study indicated that ESE- 1 was an important new contributing factor in controlling GP73 transcription in HCC cells. However, the delay in GP73 mRNA induction compared with ESE-1 after IL-1 $\beta$ stimulation in vitro (Additional file 3: Figure S3A and $\mathrm{S} 3 \mathrm{~B}$ ) and during liver inflammation in vivo (Figure $2 \mathrm{~B}$ ) indicated that other factors activated after ESE-1 worked in conjunction with ESE-1 to drive GP73 transcription in response to inflammatory stimuli. A similar finding was observed when the effects of ESE-1 on matrix metalloproteinase 13 transcriptional control were investigated in articular chondrocytes under proinflammatory stress [31].

\section{Conclusions}

This study identified that ESE-1 and GP73 expressions were induced by IL-1 $\beta$ stimulation, and ESE-1 
upregulated GP73 expression in HCC cells by directly binding to and activating its promoter. This study provided a possible mechanism for GP73 upregulation in liver diseases. More detailed investigations on the molecular mechanisms of GP73 expression is expected to contribute to understanding its functional implications in diseases and evaluating its role as a novel cancer marker.

\section{Methods}

\section{Cell culture}

Hep3B, HepG2, Huh7, and HEK 293T cells were maintained in a Dulbecco's modified Eagle's medium (Gibco, USA) supplemented with $10 \%$ fetal bovine serum (FBS) (Hyclone, USA), 100 units/mL penicillin, and 0.1\% (w/v) streptomycin. For cells treated with cytokines, 10\% FBScultured medium was removed and washed twice with PBS before adding 2\% FBS-cultured medium with IL-1 $\beta$ (Peprotech, USA).

\section{Plasmid construction and virus preparation}

Flag epitope-tagged ESE-1 from the pCI-ESE-1 plasmid [12] was subcloned into pCR3.1 plasmid with Hind III and EcoR V to produce pCR3.1-ESE-1 plasmid. pCR3.1$\triangle$ ESE-1 was generated by removing the ETS domain (272 to 354 amino acids) of ESE-1 [12]. Meanwhile, deletion ESE-1 binding site mutant promoters were formed by fusing polymerase chain reaction (PCR) based on the PGL3-basic firefly luciferase reporter vector with GP73 promoter $(-2618 /-19)$ [32]. All PCR primers are shown in Additional file 4: Table S1.

Plasmid pSuper-shESE-1, which was used to generate siRNA against ESE-1, was constructed by inserting the target sequence into pSuper (Oligoengine, USA) in site with Bgl II and Hind III. The inserted sequences are specified in Additional file 4: Table S1. Infectious shESE-1 virus particles were then generated by co-transfecting HEK293T cells with pSuper-shESE-1 and packaging plasmid [33,34]. At $48 \mathrm{~h}$ after transfection, the supernatant that contained the virus was filtered through 0.45 $\mu \mathrm{m}$ filters and was incubated with the target cells with 4 $\mathrm{mg} / \mathrm{mL}$ polybrene (Sigma, USA).

\section{Quantitative PCR}

For mRNA quantification, total RNA from cells or liver tissue was prepared with Trizol reagent according to the manufacturer's protocol (Sangon). cDNA was synthesized using a reverse transcription kit (Takara). SYBR real-time PCR was performed with specific primers (Additional file 4: Table S1) in a CFX96 Real-Time PCR Detection System (Bio-rad, USA), and glyceraldehyde 3phosphate dehydrogenase (GAPDH) or $18 \mathrm{~S}$ was used as an internal control for standardization. All reactions were performed in triplicate.

\section{Western blot analysis}

Cells were resuspended in $100 \mu \mathrm{L}$ of radio immunoprecipitation assay (RIPA) buffer (Beyotime) supplemented with protease inhibitor cocktail (Roche). Cell lysate was analyzed by using $12 \%$ SDS-PAGE and was transferred onto polyvinylidene fluoride membranes. 5B12 [7] and ab1392 (Abcam) antibodies were applied to detect GP73 and ESE-1 proteins, respectively. Protein level was normalized by GAPDH, a housekeeping protein detected by mouse anti-GAPDH monoclonal antibody (Kang Xiang, Shanghai).

\section{Transfection and reporter assays}

Cells $\left(2 \times 10^{4}\right)$ were seeded in 96-well culture plates 12 $h$ before transfection. The GP73 promoter and pCR3.1ESE-1 plasmid or $\triangle$ ESE-1 or empty vectors together with pRL-TK plasmids were cotransfected into the cells with Lipo2000 $0^{\text {ma }}$ (Invitrogen). The cells were harvested $36 \mathrm{~h}$ after transfection and were analyzed by using the Dual-glo luciferase assay kit (Promega). All transfections were performed in triplicate and repeated at least thrice. Firefly luciferase activity was normalized to renilla luciferase activity for each sample.

\section{Chromatin immunoprecipitation assay}

Chromatin immunoprecipitation (ChIP) assays were performed by using ChIP assay kit (P2078, Beyotime) following the manufacturers' instructions. Hep3B cells $\left(1 \times 10^{7}\right)$ were plated and transfected with Flag-tagged ESE-1 expression vectors and were subsequently incubated with or without $10 \mathrm{ng} / \mathrm{mL}$ IL- $1 \beta$ for $2 \mathrm{~h}$. After 36 $\mathrm{h}$, cross-linking was performed with $1 \%$ formaldehyde for $10 \mathrm{~min}$ at room temperature. Nuclei membrane was impaired, and chromatin was sheared by sonication for $7 \mathrm{~min}$ to $10 \mathrm{~min}$, producing $250 \mathrm{bp}$ to $1000 \mathrm{bp}$ fragments. Chromatin was then incubated overnight after mixing with $50 \mathrm{ul}$ of protein G/A magnetic beads (Life Technology) and $4 \mathrm{ul}$ of nonspecific mouse IgG (Chemicon) or $4 \mathrm{ul}$ of monoclonal mouse Flag antibody (F1804, Sigma) for $6 \mathrm{~h}$ at $4^{\circ} \mathrm{C}$ with rotation. DNA was precipitated using 10\% Chelex-100, which was subjected to quantitative PCR (qPCR) analysis. The primers used are listed in Additional file 4: Table S1. Negative control was performed by using the control primer of the kit.

\section{Immunohistochemical and immunofluorescence analysis}

The mouse liver inflammation model was constructed by intraperitoneally injecting $35 \mathrm{ng} / \mathrm{kg}$ of LPS and $250 \mathrm{mg} / \mathrm{kg}$ of D-galactosamine [19]. The protocol was approved by the Institutional Animal Care and Use Committee of the Guangzhou Institutes of Biomedicine and Health, Chinese Academy of Sciences (IACUC ID: 2013016). Liver tissues were collected at different time points and were subsequently fixed and sectioned ( $3 \mu \mathrm{m}$ thick). By using 
antibody 10B4 prepared in the laboratory (Additional file 5: Figure S4) and anti-mouse HRP-conjugated secondary antibody, mouse GP73 was detected and subsequently stained with 3,3'-fiaminobenzidine solution (ZSGB-BIO, Beijing). The sections were visualized with motic digital slices scanning and application system (Motic VM V1).

For immunofluorescence analysis, full-thickness human liver tissue samples were obtained from the Guangzhou Overseas Chinese Hospital. These tissue samples were fixed and sectioned ( $3 \mu \mathrm{m}$ to $4 \mu \mathrm{m}$ thick), and hematoxylineosin (HE) staining was completed in successional sections. Human GP73 was localized using antibody 5B12 and was incubated with sheep anti-mouse immunoglobulin conjugated to fluorescein isothiocyanate (Chemicon, USA). ESE1 was labeled using ab1392 antibody (Abcam) and was incubated with goat anti-rabbit antibody conjugated to rhodamine (Chemicon, USA). Nuclei were counterstained with 4,6-diamidino-2-phenylindole (DAPI; KPL, USA). The sections were viewed with a confocal microscope (LSM 710; Zeiss, Germany).

\section{Statistical analysis}

Data were reported as mean \pm standard error of at least three independent experiments, and statistical analysis was performed by using ANOVA, followed by Student's t-test $\left({ }^{*}: \mathrm{p}<0.05 ;{ }^{* * * *}: \mathrm{p}<0.01 ;{ }^{* * * *}: \mathrm{p}<0.001\right)$.

\section{Additional files}

Additional file 1: Figure S1. The correlation of ESE-1 and GP73 expression in other hepatocytes. Human hepatocytes: Bel-7402, QSG-7701, HL-7702(L-02); Mouse hepatocytes: Hep 1-6, AML-12.

Additional file 2: Figure S2. The location of ESE-1 protein in Нер3B and Huh7 cells with or without IL-1 $\beta$ stimulation.

Additional file 3: Figure S3. The time course expression of ESE-1 and GP73 mRNA in Hep3B cells with IL-1 $\beta$ stimulation.

Additional file 4: Table S1. Sequences of PCR primers used in this study. Additional file 5: Figure S4. Validation of mouse GP73 (10B4) antibody. (A) Flag epitope-tagged pCR3.1-mGP73 plasmids were transfected into 293T cells; mouse GP73 (mGP73) expression was detected using anti-flag antibody (F1804, Sigma) or anti-mGP73 antibody (10B4) with Western blot. (B) The location of mGP73 was tested using 10B4 antibody in Hep1-6 cells with immunocytochemistry. Black arrows signified the location of mouse GP73 protein.

\section{Competing interests}

The authors declare that they have no competing interests.

\section{Authors' contributions}

FW, QL and TP conceived the research design and carried out the experiments, as well as analyzed the data. FW and TP wrote, reviewed and/or revised this manuscript. FW, QL, YG, LBH, HZ, PO and TP provided administrative, technical and material support. All authors read and approved the final manuscript.

\section{Acknowledgements}

The authors sincerely acknowledge the generous support and technical assistance provided by the other members of the lab. This work was supported by Guangdong Province \& Chinese Academy of Sciences Comprehensive Strategic Cooperation Project (NO.2012B090400012) and Guangdong Provincial Health Bureau of Medical Scientific Research Fund (A2011351).

\section{Author details}

${ }^{1}$ State Key Laboratory of Respiratory Disease, Guangzhou Institutes of Biomedicine and Health, Chinese Academy of Sciences, Guangzhou 510530, China. ${ }^{2}$ Guangzhou Hoffmann Institute of Immunology, College of Basic Sciences, Guangzhou Medical University, Guangzhou 510182, China. ${ }^{3}$ Guangzhou Overseas Chinese Hospital, Guangzhou 510630, China. ${ }^{4}$ Division of Immunology, Beth Israel Deaconess Medical Center and Harvard Medical School, Boston, Massachusetts 02215, USA. ${ }^{5}$ Max Planck Institute for Molecular Biomedicine, Röntgenstraße 20, 48149 Münster, Germany.

Received: 29 September 2014 Accepted: 28 November 2014 Published: 8 December 2014

\section{References}

1. Norton PA, Comunale MA, Krakover J, Rodemich L, Pirog N, D'Amelio A, Philip R, Mehta AS, Block TM: N-linked glycosylation of the liver cancer biomarker GP73. J Cell Biochem 2008, 104:136-149.

2. Kladney RD, Bulla GA, Guo L, Mason AL, Tollefson AE, Simon DJ, Koutoubi Z, Fimmel CJ: GP73, a novel Golgi-localized protein upregulated by viral infection. Gene 2000, 249:53-65.

3. Kladney RD, Cui X, Bulla GA, Brunt EM, Fimmel CJ: Expression of GP73, a resident Golgi membrane protein, in viral and nonviral liver disease. Hepatology 2002, 35:1431-1440.

4. Iftikhar R, Kladney RD, Havlioglu N, Schmitt-Graff A, Gusmirovic I, Solomon $H$, Luxon BA, Bacon BR, CJ F: Disease- and cell-specific expression of GP73 in human liver disease. Am J Gastroenterol 2004, 99:1087-1095.

5. Block TM, Comunale MA, Lowman M, Steel LF, Romano PR, Fimmel C, Tennant BC, London WT, Evans AA, Blumberg BS, Dwek RA, Mattu TS, Mehta AS: Use of targeted glycoproteomics to identify serum glycoproteins that correlate with liver cancer in woodchucks and humans. Proc Natl Acad Sci U S A 2005, 102:779-784.

6. Marrero JA, Romano PR, Nikolaeva O, Steel L, Mehta A, Fimmel CJ, Comunale MA, D'Amelio A, Lok AS, Block TM: GP73, a resident Golgi glycoprotein, is a novel serum marker for hepatocellular carcinoma. J Hepatol 2005, 43:1007-1012.

7. Gu YL, Chen WL, Zhao Y, Chen LY, Peng T: Quantitative analysis of elevated serum Golgi protein-73 expression in patients with liver diseases. Ann Clin Biochem 2009, 46:38-43.

8. Mao YLY,HY, Xu HF, Lu X, Sang XT, Du SD, Zhao HT, Chen W, Xu Y, Chi TY, Yang ZY, Cai JQ, Li H, Chen JG, Zhong SX, Mohanti SR, Lopez-Soler R, Millis $J M$, Huang JF, Zhang HB: Golgi protein $73(\mathrm{GOLPH} 2)$ is a valuable serum marker for hepatocellular carcinoma. Gut 2010, 59:1687-1693.

9. Liang HY, Block TM, Wang MJ, Nefsky B, Long R, Hafner J, Mehta AS, Marrero J, Gish R, Norton PA: Interleukin- 6 and oncostatin M are elevated in liver disease in conjunction with candidate hepatocellular carcinoma biomarker GP73. Cancer Biomark 2012, 11:161-171.

10. Wright LM, Yong SR, Picken MM, Rockey D, Fimmel CJ: Decreased survival and hepato-renal pathology in mice with C-terminally truncated GP73 (GOLPH2). Int J Clin Exp Pathol 2009, 2:34-47.

11. Wright LM, Huster D, Lutsenko S, Wrba F, Ferenci P, Fimmel CJ: Hepatocyte GP73 expression in Wilson disease. J Hepatol 2009, 51:557-564.

12. Oettgen P, Alani RM, Barcinski MA, Brown L, Akbarali Y, Boltax J, Kunsch C, Munger K, Libermann TA: Isolation and characterization of a novel epithelium-specific transcription factor, ESE-1, a member of the ets family. Mol Cell Biol 1997, 17:4419-4433.

13. Oliver JR, Kushwah R, Hu J: Multiple roles of the epithelium-specific ETS transcription factor, ESE-1, in development and disease. Lab Invest 2012, 92:320-330

14. Grall F, Gu XS, Tan $\sqcup$, Cho JY, Inan MS, Pettit AR, Thamrongsak U, Choy BK, Manning C, Akbarali Y, Zerbini L, Rudders S, Goldring SR, Gravallese EM, Oettgen $\mathrm{P}$, Goldring MB, Libermann TA: Responses to the proinflammatory cytokines interleukin-1 and tumor necrosis factor a in cells derived from rheumatoid synovium and other joint tissues involve nuclear factor kappa B-mediated induction of the ets transcription factor ESE-1. Arthritis Rheum 2003, 48:1249-1260.

15. Grall FT, Prall WC, Wei WJ, Gu XS, Cho JY, Choy BK, Zerbini LF, Inan MS, Goldring SR, Gravallese EM, Goldring MB, Oettgen P, Libermann TA: The Ets transcription factor ESE-1 mediates induction of the COX-2 gene by LPS in monocytes. Febs $J$ 2005, 272:1676-1687.

16. Rudders S, Gaspar J, Madore R, Voland C, Grall F, Patel A, Pellacani A, Perrella MA, Libermann TA, Oettgen P: ESE-1 is a novel transcriptional mediator of 
inflammation that interacts with NF- $\mathrm{kB}$ to regulate the inducible nitric-oxide synthase gene. J Biol Chem 2001, 276:3302-3309.

17. Peng HTL, Osaki M, Zhan Y, ljiri K, Tsuchimochi K, Otero M, Wang H, Choy BK, Grall FT, Gu X, Libermann TA, Oettgen P, Goldring MB: ESE-1 is a potent repressor of type II collagen gene (COL2A1) transcription in human chondrocytes. J Cell Physiol 2008, 215:562-573.

18. Longoni NSM, Albino D, Civenni G, Malek A, Ortelli E, Pinton S, Mello-Grand M, Ostano P, D'Ambrosio G, Sessa F, Garcia-Escudero R, Thalmann GN, Chiorino G, Catapano CV, Carbone GM: ETS transcription factor ESE1/ELF3 orchestrates a positive feedback loop that constitutively activates NF-kappaB and drives prostate cancer progression. Cancer Res 2013, 73:4533-4547.

19. Gonzalez-Teran B, Cortes JR, Manieri E, Matesanz N, Verdugo A, Rodriguez ME, Gonzalez-Rodriguez A, Valverde A, Martin P, Davis RJ, Sabio G: Eukaryotic elongation factor 2 controls TNF-alpha translation in LPS-induced hepatitis. J Clin Invest 2013, 123:164-178.

20. Hu L, Li L, Xie H, Gu Y, Peng T: The Golgi localization of GOLPH2 (GP73/ GOLM1) is determined by the transmembrane and cytoplasmic sequences. Plos One 2011, 6:e28207.

21. Prescott JD, Koto KSN, Singh M, Gutierrez-Hartmann A: The ETS transcription factor ESE-1 transforms MCF-12A human mammary epithelial cells via a novel cytoplasmic mechanism. Mol Cell Biol 2004, 24:5548-5564.

22. Prescott JD, Poczobutt JM, Tentler JJ, Walker DM, Gutierrez-Hartmann A: Mapping of ESE-1 subdomains required to initiate mammary epithelial cell transformation via a cytoplasmic mechanism. Mol Cancer 2011, 10:103.

23. Bishayee A: The role of inflammation and liver cancer. Adv Exp Med Biol 2014, 816:401-435.

24. Aravalli RN: Role of innate immunity in the development of hepatocellular carcinoma. World I Gastroentero 2013, 19:7500-7514.

25. Deng Y, Du Y, Zhang Q, Han X, Cao GW: Human cytidine deaminases facilitate hepatitis $B$ virus evolution and link inflammation and hepatocellular carcinoma. Cancer Lett 2014, 343:161-171.

26. Nakagawa H, Maeda S: Inflammation- and stress-related signaling pathways in hepatocarcinogenesis. World J Gastroentero 2012, 18:4071-4081.

27. Wang H, Fang RH, Cho JY, Libermann TA, Oettgen P: Positive and negative modulation of the transcriptional activity of the ETS factor ESE-1 through interaction with p300, CREB-binding protein, and Ku 70/86. J Biol Chem 2004, 279:25241-25250.

28. Choi SG, Yi Y, Kim YS, Kato M, Chang J, Chung HW, Hahm KB, Yang HK, Rhee HH, Bang YJ, Kim SJ: A novel ets-related transcription factor, ERT/ESX/ESE-1, regulates expression of the transforming growth factor-b type II receptor. J Biol Chem 1998, 273:110-117.

29. Jean-Philippe Coppe CA, Semeiks J, Baehner FL, Bayani N, Judith C, Benz CC, Gray JW, Neve RM: ERBB receptor regulation of ESX/ELF3 promotes invasion in breast epithelial cells. The Open Cancer Journal 2010, 3:89-100.

30. Darius M, Walker JMP, Gonzales MS, Henrick H, Arthur G-H: ESE-1 is required to maintain the transformed phenotype of MCF-7 and ZR-75-1 human breast cancer cells. The Open Cancer Journal 2010, 3:77-88.

31. Otero M, Plumb DA, Tsuchimochi K, Dragomir CL, Hashimoto K, Peng HB, Olivotto E, Bevilacqua M, Tan LJ, Yang ZY, Zhan Y, Oettgen P, Li Y, Marcu KB, Goldring MB: E74-like factor 3 (ELF3) impacts on matrix metalloproteinase 13 (MMP13) transcriptional control in articular chondrocytes under proinflammatory stress. J Biol Chem 2012, 287:3559-3572.

32. Gong Y, Long $\mathrm{Q}$, Xie H, Zhang T, Peng T: Cloning and characterization of human Golgi phosphoprotein 2 gene (GOLPH2/GP73/GOLM1) promoter. Biochem Biophys Res Commun 2012, 421:713-720.

33. Brummelkamp TR, Bernards R, Agami R: A system for stable expression of short interfering RNAs in mammalian cells. Science 2002, 296:550-553.

34. Hu LB, Yao W, Wang F, Rong X, Peng T: GP73 is upregulated by Hepatitis C Virus (HCV) infection and enhances HCV secretion. Plos One 2014, 9:e90553.

doi:10.1186/2045-3701-4-76

Cite this article as: Wang et al: Epithelium-Specific ETS (ESE)-1 upregulated GP73 expression in hepatocellular carcinoma cells. Cell \& Bioscience 2014 4:76.

\section{Submit your next manuscript to BioMed Central and take full advantage of:}

- Convenient online submission

- Thorough peer review

- No space constraints or color figure charges

- Immediate publication on acceptance

- Inclusion in PubMed, CAS, Scopus and Google Scholar

- Research which is freely available for redistribution 